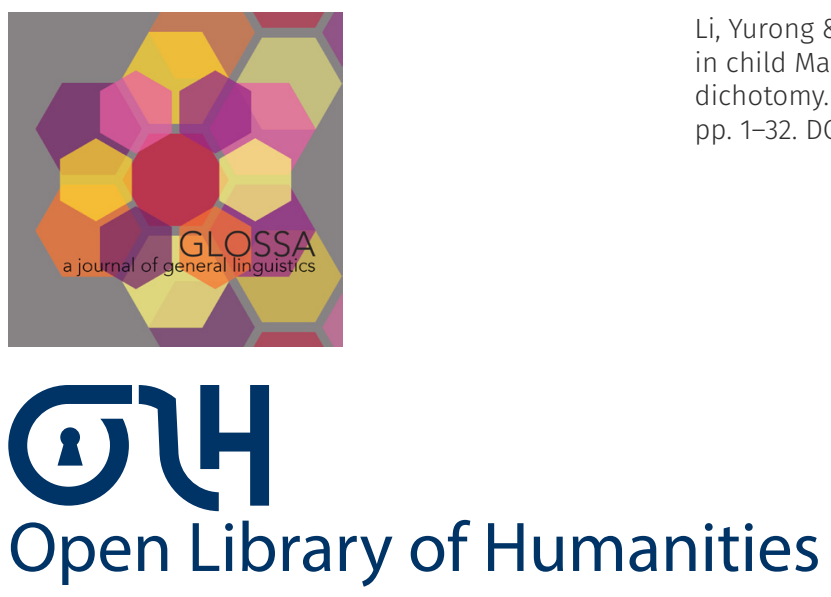

\title{
Donkey pronouns in child Mandarin: Insights into the existential/universal dichotomy
}

Yurong Li, Department of Foreign Languages and Literatures, Tsinghua University, CN, yr-li18@mails.tsinghua.edu.cn Peng Zhou (corresponding author), Department of Foreign Languages and Literatures, Tsinghua University, CN, zhoupeng1892@tsinghua.edu.cn

Mingming Liu, Department of Foreign Languages and Literatures, Tsinghua University, CN, markliu@tsinghua.edu.cn

Donkey pronouns and plural definites show similarities in their semantic interpretation. The parallels between the two elements seem to suggest a unified analysis. Studies of children's understanding of plural definites show that children initially interpret plural definites existentially rather than universally. The findings invite us to ask whether children also exhibit a preference for interpreting donkey pronouns existentially. Two experiments were conducted to compare children' and adults' interpretation of donkey pronouns in conditional and relativeclause donkey sentences. The results of Experiment 1 show that children preferred the $\exists$-reading, whereas adults entertained the $\forall$-reading for both types of donkey sentences in upwardentailing contexts. Experiment 2 examined whether monotonicity influences the interpretation of donkey pronouns by creating a downward-entailing context. The findings were that in a downward-entailing context both children and adults preferred the $\exists$-reading. The findings led us to propose that the $\exists$-reading is perhaps the basic semantics of donkey pronouns while the $\forall$-reading is derived, and we suggest that the derivational path is bridged by free choice strengthening. The findings were then discussed in relation to the analysis of homogeneity and plural predication by Bar-Lev (2020).

Glossa: a journal of general linguistics is a peer-reviewed open access journal published by the Open Library of Humanities. () 2021 The Author(s). This is an open-access article distributed under the terms of the Creative Commons Attribution 4.0 International License (CC-BY 4.0), which permits unrestricted use, distribution, and reproduction in any medium, provided the original author and source are credited. See http://creativecommons.org/licenses/by/4.0/. 


\section{Introduction}

Since Geach (1962), much research has investigated the interpretation of donkey sentences as in (1) and (2). In particular, research has focused on the semantics of donkey pronouns (boldfaced below) in these sentences.

(1) If a farmer owns a donkey, he beats it. (Conditional donkey sentence)

(2) Every farmer who owns a donkey beats it. (Relative-clause donkey sentence)

It has been widely acknowledged that (at least) three factors contribute to the interpretational preference of a donkey pronoun: monotonicity of the matrix quantifier, lexical semantics of the predicate with which the donkey pronouns are combined, and the discourse contexts in which the sentence is produced, which we discuss below.

First, monotonicity of the quantifier plays a role in the interpretation of donkey pronouns (Rooth 1987; Kanazawa 1994; Krifka 1996; Yoon 1996; Geurts 2002; a.o.). Quantifiers like every and no exhibit different monotonicity in their nuclear scope (the VP argument), with every being upward entailing (every student danced happily entails every student danced) but with no being downward entailing (no student danced happily is entailed by no student danced). The different monotonicity in the nuclear scope leads to different interpretations of the donkey pronoun therein (Rooth 1987). For example, sentence (3a) with the quantifier every favors a universal reading of the donkey pronoun, meaning that every farmer that owns a donkey beats all of his donkeys, as in (3b); while an existential reading of the donkey pronoun is preferred for sentence (4a) with the quantifier no, meaning that no farmer that owns a donkey beats any of his donkeys, as in (4b). This interpretational difference between (3) and (4) leads to the generalization that donkey sentences with quantifiers that are downward entailing in the nuclear scope prefer an existential interpretation of the donkey pronoun, whereas donkey sentences with quantifiers that are upward entailing in the nuclear scope favor a universal reading (Rooth 1987; Krifka 1996; Yoon 1996). ${ }^{1}$

(3) a. Every farmer that owns a donkey beats it.

b. Every farmer that owns a donkey beats all of his donkeys.

a. No farmer that owns a donkey beats it.

b. No farmer that owns a donkey beats any of his donkeys.

\footnotetext{
${ }^{1}$ Kanazawa (1994) and Geurts (2002) further observe that donkey sentences with weak determiners like some, a few, at least $n$ only have an existential reading; whereas donkey sentences with universal determiners like every, all, not every, prefer a universal reading, although they may have an existential reading, too. It seems that some is an exception to the generalization that quantifiers that are upward entailing in the nuclear scope prefer a universal interpretation. However, for reasons of space, we only focus on every and no in this paper and will leave investigations of other quantifiers for future research.
} 
In addition, according to Chierchia (1992) and Gawron et al. (1991), discourse contexts also play a role in the interpretation of donkey pronouns (see Champollion et al. 2019 for a recent discussion). An example is given in Chierchia (1992: 116): in order to channel the farmers' aggressiveness, the local psychotherapist recommended that every farmer who has a donkey should beat it. In such a context, the farmers according to the recommendation should beat at least one of their donkeys but not necessarily all of them, despite the fact the sentence in isolation prefers a universal construal (cf. (3)). Another example of this kind is that for scientists and health officials, their attitudes towards Zika fly may decide how they understand the donkey pronoun in (5). For scientists who are looking for a sample, sentence (5) means that the one who catches a Zika fly should bring at least one of the flies. While for health department officials who are trying to eradicate the species, the same sentence is true only if in all the worlds where the rules are satisfied all the Zika flies should be brought to the speaker (Gawron et al. 1991).

Anyone who catches a Zika fly should bring it to me. ${ }^{2}$

The third factor that might impact the interpretation of donkey pronouns is the lexical semantics of the predicate with which the donkey pronoun is combined. ${ }^{3}$ Yoon (1996) proposed that partial and total predicates contribute to the interpretational difference between the existential and the universal interpretations of donkey pronouns. More specifically, donkey sentences with a total predicate in their nuclear scope tend to be interpreted universally and those with a partial predicate favor an existential interpretation. For instance, suppose there are 3 boys, each of whom has 5 baseball cards, and each soils at least one of the baseball cards while playing in the mud, the donkey sentence in (6) seems to be a true description of this situation, indicating that with the partial predicate soiled, it favors an existential reading. Whereas for the donkey sentence in (7), it seems to be a true description of a situation where there are 3 boys, each of whom has 5 baseball cards, and all the 3 boys keep all of their cards clean while playing in the mud. However, if the 3 boys each doesn't keep at least one of the cards clean, the sentence becomes false. This interpretational difference indicates that with the total predicate keep clean, the donkey sentence in (7) prefers a universal reading.

\footnotetext{
2 As one reviewer correctly pointed out, in the corresponding negative sentence No one who catches a Zika fly might keep it to themselves, the donkey pronoun cannot be interpreted with a non-existential reading, even from the scientist's perspective. The asymmetry between positive and negative donkey sentences closely parallels (among many other parallels to be discussed immediately in the next section) the case of plural definites (Bar-Lev 2020), suggesting the two should be treated analogously. We thank the reviewer for this insightful observation.

${ }^{3}$ Current theories of homogeneity and non-maximality tend to subsume the apparent role of predicate type under a general theory of non-maximality as regulated by contextual factors (Križ 2016; Champollion et al. 2019, a.o.). For example, one could argue that for sentences (6) and (7) in default contexts there is no serious contextual difference between soiling only some cards and soiling all (it may be considered bad behavior even if you soiled just one card), while there is a serious difference between keeping just some cards clean (bad behavior) and keeping all cards clean (good behavior). We thank an anonymous reviewer for raising this point.
} 
(6) Every boy who had a baseball card in their pockets soiled it while playing in the mud.

Every boy who had a baseball card in their pockets kept it clean while playing in the mud.

(Yoon 1996: 222)

To take stock, previous research suggests that donkey pronouns exhibit the $\exists / \forall$ dichotomy. However, in the theoretical literature the question of how the donkey pronouns are assigned the correct interpretations has been much debated (Lewis 1975; Evans 1977; 1980; Parsons 1978; Cooper 1979; Kamp 1981; Heim 1982; 1990; Groenendijk \& Stokhof 1991; Chierchia 1992; 1995; 2000; Brasoveanu 2008; Champollion et al. 2019). The present paper offers a novel perspective into the theoretical debate by turning to child language acquisition. More specifically, we investigated Mandarin-speaking children's interpretation of donkey pronouns, with an attempt to show how theoretical analyses of donkey pronouns could raise interesting questions for child language acquisition, and how data from child language acquisition can, in turn, inform linguistic theories.

Previous experimental studies of children's interpretation of donkey sentences (Conway \& Crain 1995a; b; Crain et al. 1996) did not present a clear-cut picture of children's knowledge of donkey pronouns. For instance, Conway and Crain (1995a; b) reported that in contrast to adults, English-speaking children accepted the existential reading of donkey pronouns for relativeclause donkey sentences $86 \%$ of the time, however, in the same study the acceptance rate of the existential reading of donkey pronouns in conditional donkey sentences was only $46 \%{ }^{4}$

The findings by Crain et al. (1996) and Conway and Crain (1995a; b) led us to ask whether the existential reading might indeed be the basic interpretation of donkey pronouns, although the existential-preference is instantiated only for donkey pronouns in relative-clause donkey sentences. We wish to suggest that the question can be approached by examining a related phenomenon - the interpretation of plural definites. In particular, we adopt the idea proposed by Krifka (1996) and Yoon (1996) that the two should be analyzed analogously. This line of reasoning is supported by the parallels between donkey pronouns and plural definites from both a theoretical and an experimental perspective. Like donkey pronouns, plural definites also exhibit the $\exists / \forall$ dichotomy along the three aspects discussed above. In addition, empirical studies of children's understanding of plural definites showed that children initially interpret plural definites existentially (or non-maximally), rather than universally (Karmiloff-Smith 1981; Caponigro et al. 2012; Tieu et al. 2019). The findings invite us to ask whether children also interpret donkey pronouns existentially as they do with plural definites. If children indeed exhibit a preference for

\footnotetext{
${ }^{4}$ We suspect that this relatively low acceptance rate of the existential reading of donkey pronouns in conditional donkey sentences might be due to their experimental design, with a small sample of child participants $(n=15)$ and with a huge variation in age (ranging from $3 ; 7$ to $5 ; 5$ ).
} 
the existential reading of donkey pronouns, this might provide evidence for a unified analysis of donkey pronouns and plural definites (or for a common mechanism behind the two phenomena as in Champollion et al. 2019).

Before presenting our experimental studies, we first discuss how the three factors, monotonicity, lexical semantics and discourse contexts, influence the interpretation of plural definites in a similar way as they do with donkey pronouns; and then we review prior experimental research on English-speaking children's understanding of plural definites.

\section{$2 \exists / \forall$ Dichotomy of Plural Definites}

Sentences with plural definites also exhibit the $\exists / \forall$ dichotomy. The quantificational force associated with plural definites is also affected by the same three factors.

First, example (8) and (9) are used to illustrate the role of monotonicity in the interpretation. The positive sentence in (8), which contains the plural definite his presents in an upward entailing environment, favors the reading that all of the presents were found by each boy that receives the presents, whereas the negative sentence in (9), where the same plural definite occurs in a downward entailing environment, entertains the meaning that none (not any) of the presents were found by the boys who own the presents (Križ 2015). Note that the plural definite contains a bound pronoun, and thus his presents in (9) has to be interpreted as having a narrow scope existential reading. This leads to the phenomenon named homogeneity that plural definites have universal readings in positive contexts but existential readings in negative contexts (Löbner 1987; Schwarzschild 1994; Krifka 1996; Gajewski 2005; Magri 2014; Križ 2015; 2016; Križ \& Spector 2021).

(8) Every boy found his presents. $\approx$ Every boy found [all of his presents].

(9) No boy found his presents. $\quad \approx$ No boy found [any of his presents].

Second, lexical semantics also plays a role in the interpretation of plural definites, patterning again with donkey pronouns. According to Yoon $(1994 ; 1996)$, a total predicate applies to all parts of what is denoted by the plural NP while a partial predicate applies to some but not necessarily all parts of what is denoted by the plural NP. Therefore, affirmative sentences with total predicates prefer the universal reading whereas affirmative sentences with partial predicates favor the existential reading. The examples are given in (10) and (11), where the partial predicate spotted not necessarily needs all the glasses to be spotted but the total predicate spotless requires all of the glasses to be clean. Yoon (1994) conducted an experimental study to investigate whether lexical semantics impacts the interpretation of both plural definites and donkey pronouns. In the study, the participants were presented with both donkey sentences with total/partial predicates and the plural subject-predicate sentences with total/partial predicates, and they were asked to 
judge whether these sentences truthfully described a given situation. The major findings were that for plural definites adults assigned the universal reading to those with total predicates $84 \%$ of the time, and they assigned the existential reading to those with partial predicates $82 \%$ of the time; for donkey sentences, they assigned the universal reading to those with total predicates $74 \%$ of the time, and they assigned the existential reading to those with partial predicates $78 \%$ of the time. The similar patterns between donkey pronouns and plural definites obtained from the study provided empirical support not just for the effect of lexical semantics on the interpretation of donkey pronouns and plural definites, but also for the parallel between the two.

(10) The glasses are spotted.

(11) The glasses are spotless.

(Yoon 1996: 222)

In addition, discourse contexts can also influence the interpretation of sentences with plural definites. For example, Krifka (1996) and Malamud (2012) observe that the role played by lexical semantics of the predicate may be overridden by contexts (cf. footnote 3). Suppose there are three doors to the safe of a bank arranged in parallel, then the sentence with the partial predicate open is true if at least two doors are open; whereas if the three doors are arranged in sequence, then the sentence is true if each of the three doors is open, as manifested in the contexts in (12a) and (12b) respectively.

(12) The doors (to the safe) are open.

a. Context: the doors are arranged in sequence mm Every door is open.

b. Context: the doors are arranged in parallel $m \rightarrow$ Some of the doors are open.

The parallels between donkey pronouns and plural definites regarding the three aspects point to a unified analysis of the two. ${ }^{5}$ In fact, there is a line of research that analyzes donkey pronouns as numberless definites (Davies 1981; Lappin 1989; Neale 1990; Lappin \& Francez 1994; Yoon 1994; 1996; Krifka 1996). According to this view, donkey pronouns are syntactically singular but semantically include both singular and plural individuals, and their singular form is triggered by purely syntactic agreement (Lappin 1989; Neale 1990). For instance, the donkey pronoun in the sentence Every man who owns a donkey beats it according to the numberless view is actually the donkey or donkeys (he owns). This proposal differs from earlier E-type pronoun analyses in that under many E-type analyses the donkey pronoun produces a uniqueness presupposition (Evans 1977; 1980; Parsons 1978; Cooper 1979), whereas a numberless definite, since it can be either singular or plural, avoids the problem of triggering unpleasantly strong uniqueness presuppositions.

\footnotetext{
${ }^{5}$ Chierchia (2020) developed a unified theory of plural definites, bare plurals and donkey pronouns by analyzing them as a case of free choice but with the details of the implementation significantly different from Bar-Lev's.
} 
It's worth pointing out that there is also a tradition that analyzes donkey pronouns as singular definites and deals with the unwelcome uniqueness entailments by means of situation semantics (Heim 1990; Elbourne 2001). For instance, in Heim's framework, relative-clause donkey sentences involve two quantifying operators. One is the QDet which binds the variable introduced by the head noun and the other is an implicit quantifier with existential or universal force that binds minimal situations or cases. Whether the situations or cases are universally or existentially quantified is determined by pragmatics. However, we wish to note that under this analysis it is unclear how the parallels between donkey pronouns and plural definites can be accounted for. In addition, it remains unclear how this proposal can deal with children's data in both positive and negative contexts reported in the current paper. For these reasons, the current paper follows the line of proposals that highlight the similarities between the two and explicitly takes donkey pronouns as numberless definites (Krifka 1996; Yoon 1996). ${ }^{6}$

Before concluding the section, we would like to mention that there are also challenges for analyzing donkey pronouns as numberless definites (Kanazawa 2001). ${ }^{7,8}$ First, collective predicates pose a challenge. Given the analysis of Yoon (1994) and Krifka (1996) in which a donkey pronoun is interpreted as a numberless sum-denoting individual, it should be possible for a donkey pronoun to be compatible with a collective predicate. However, this is not the case, as illustrated by example (13a), in contrast to (13b) with a real plural definite. Here, we wish to point out a preliminary solution discussed in Brasoveanu (2008) following a suggestion by Neale (1990). We can assume that singular donkey pronouns always introduce a distributivity operator, which in (13a) would require each atomic donkey in the maximal sum of donkeys to be rounded up at night. Since the collective predicate round up cannot apply to atomic individuals, (13a) is infelicitous.

(13) a. \#Every farmer who owns a donkey rounds it up at night.

b. Every farmer rounds the donkeys up at night.

Another challenge for a unification of plural definite and donkey pronoun is that they do not behave similarly with respect to certain quantificational determiners like some. Quantifiers like

\footnotetext{
${ }^{6}$ There is of course difference between donkey pronouns analyzed as numberless definites and actual plural definites, as an anonymous reviewer emphasizes. The two differ in their denotations and presuppositions. In the former case, there are both singular and plural individuals, whereas a plural definite like the students denotes the maximal sum of all students in the domain of discourse (Sharvy 1980; Link 1983), and presupposes we are dealing with more than one student.

7 We want to thank an anonymous reviewer for emphasizing these challenges. We acknowledge that we do not have solutions to the problems, and we will have to leave them for further research. Despite the challenges, we believe that given the close parallel between donkey pronouns and plural definites, it might be worthwhile to pursue an analysis towards unification.

${ }^{8}$ Kanazawa (2001) pointed out a number of challenges, and here we list the most prominent one.
} 
some are exceptions to the generalization that quantifiers with right upward monotonicity prefer a universal reading (see footnote 1). For example, when in the nuclear scope of some, the donkey pronoun in (14a) is interpreted existentially, saying that some farmer who owns a donkey beats at least one of his donkeys, whereas the plural definite noun phrase in (14b) prefers a universal interpretation which says that some girl read all the books. This difference between donkey pronouns and plural definites with respect to some poses another challenge we cannot resolve in the paper.

(14) a. Some farmer who owns a donkey beats it.

b. Some girl read the books.

To summarize, we have discussed how the three factors, monotonicity, lexical semantics and discourse contexts, influence the interpretation of plural definites in a similar way as they do with donkey pronouns. These theoretical considerations provide important insights into a unified analysis of the two. We also discussed some unresolved challenges for such a unification. In the following sections, we turn to child language acquisition to see if child language data can inform us about the theoretical analysis of donkey pronouns and plural definites. As we will see, our results from child language acquisition offer additional support for a unification, despite the challenges.

\section{Empirical Studies of Plural Definites}

As discussed in Section 1, prior research on children's interpretation of donkey sentences found that 3- to 5-year-old English-speaking children favored the existential reading of donkey pronouns, at least in relative-clause donkey sentences (Conway \& Crain 1995a; b; Crain et al. 1996). Similar preference was observed in children's interpretation of plural definites in both positive (upward entailing) and negative (downward entailing) sentences, which we discuss below.

Karmiloff-Smith (1981) and Caponigro et al. (2012) reported that children allowed more existential readings than adults in their judgment of positive sentences containing plural definites. For example, Karmiloff-Smith (1981) investigated both French-speaking children's comprehension and production, and found that French-speaking children between 3;0-5;6 years of age did not interpret plural definites universally and she hypothesized that this is because the plural definite article les was only associated with pluralization at this stage. The maximal/universal reading of the plural definite les emerges between 5 to 8 years of age. In addition, using an act out task, ${ }^{9}$

\footnotetext{
${ }^{9}$ In the paper by Caponigro et al. (2012), they reported two experiments, one using a Truth Value Judgment Task (TVJT) and one using an act-out task. However, using the TVJT they found that even adult controls did not always access maximal readings for the definite plural descriptions and free relatives, for which they suggest that the problem may lie in the nature of the TVJT since there might be a presupposition of homogeneity violation with respect to plural definite descriptions in the GAP context. In addition, in the TVJT even 7-year-olds performed around chance level. This confusion in the TVJT led us to only review and report the act-out task in their study.
} 
Caponigro et al. (2012) investigated how English-speaking children interpreted plural definite descriptions and free relatives. In the experimental task, a plastic bucket and a colorful plate were placed in front of the participants, and in each of the container there were four pieces of plastic fruit (an orange, an apple, a banana, and a strawberry). For the plural description trials the participants were asked 'Could you give me the things in the bucket/on the plate?' The results showed that English-speaking 4- and 5-year-old children did not initially interpret plural definites maximally and that adult-like interpretation of plural definites did not emerge in children until 6 or 7 years of age. To account for the findings, Caponigro et al. (2012) proposed that young children entertained the non-maximal (existential) interpretation of plural definites because they associated plural NPs with a set of plural atomic individuals with no maximal individuals and the young children were still struggling to map the conceptual representations of plural individuals to the relevant linguistic structure. Concerning the interpretation of plural definites in both upward and downward entailing contexts, Tieu et al. (2019) designed a Truth Value Judgment Task (TVJT) to investigate how French-speaking children and adults interpreted positive and negative sentences containing plural definites. Participants were asked to judge the description by the puppet who would utter a test sentence containing a plural definite description (e.g. les ballons 'the balloons'), an existentially quantified noun phrase (e.g. certains ballons 'some balloons') or a universally quantified noun phrase (e.g. tous les ballons 'all of the balloons'). It was found that the majority of the adults interpreted plural definites homogeneously (i.e., they rejected both the positive and negative descriptions with plural definites uniformly, such as The trucks are blue and The trucks aren't blue in the GAP context, e.g., in a context where 2 of the 4 cars are red) and some of the adults interpreted plual definites universally but none treated plural definites as existentials. While for the children's responses, they observed two groups of children: one group ( 8 children) interpreted the plural definites existentially ${ }^{10}$ and the other group (16 children) assigned a homogeneous reading to plural definites. However, no children were found to adopt the universal reading. To be more specific, when presented with a mixed context where some but not all of the cars were red, eight French-speaking children judged the positive sentence The cars are red to be a true description of the context; by contrast, no children judged the negative sentence The cars are not red to be true in the same context. Taken together, prior studies on children's understanding of plural definites converge that 4- to 5-year-old children exhibited a strong tendency to assign an existential reading to plural definites, in both upward entailing and downward entailing contexts. ${ }^{11}$

10 The finding that in this context where 2 out of the 4 cars are red children accepted the test sentence 'The cars are red' can rule out an analysis where definite plurals (when underspecified and/or non-maximal) converge loosely on a 'several' or 'most' reading.

11 There is one study by Munn, Miller and Schmitt (2006), which showed that 3-year-old English-speaking children and Spanish-speaking children correctly interpreted plural definites maximally. However, the study had quite a few shortcomings, as discussed in detail by Caponigro et al. (2010; 2012). 
The tendency exhibited by children invites us to ask about their interpretation of donkey pronouns. As discussed, Crain et al. (1996) and Conway and Crain (1995a; b) provided some preliminary evidence that English-speaking children exhibited a preference for the existential reading of donkey pronouns. However, their study mainly focused on donkey pronouns in positive sentences without looking at children's interpretation of donkey pronouns in negative sentences. In addition, the sample size of the participants was relatively small in their study, in which 15 children participated in the study with a large age range from $3 ; 7$ to $5 ; 5$. In the present study, we were interested to find out whether children exhibit a preference for the existential reading in both positive and negative sentences as they do with plural definites. To the best of our knowledge, this study is the first to investigate children's understanding of donkey pronouns in both positive and negative contexts. More specifically, the present study aimed to provide a cross-linguistic perspective on children's interpretation of donkey pronouns by looking at a lesser-studied language, Mandarin Chinese. If cross-linguistically children exhibit the same initial preference for the existential reading of donkey pronouns, then this might shed light on the nature of donkey pronouns. In the present paper, we focused on the cross-linguistic similarities of donkey pronouns, and we sought to provide an analysis of donkey anaphora in general. ${ }^{12}$ To address the research questions, two experiments were conducted, in which donkey pronouns occurred in both an upward entailing (Experiment 1) and a downward entailing context (Experiment 2).

\section{Experiment 1}

Experiment 1 investigated how Mandarin-speaking children interpreted donkey pronouns in an upward entailing (UE) context (i.e., whether they exhibited a preference for the existential reading of donkey pronouns).

\footnotetext{
${ }^{12}$ Previous studies of Mandarin donkey sentences mainly focused on the analysis of conditional sentences with wh-indefinites in the antecedents (Cheng \& Huang 1996; 2020; Pan \& Jiang 2015), including bare conditionals, ruguo-conditionals, and dou-conditionals. It is also a much-debated issue as to whether wh-elements constitute as eligible donkey anaphora in Mandarin (see detailed discussions in Cheng \& Huang 1996; 2020; Pan \& Jiang 2015). To avoid potential theoretical disputes, the present study chooses pronouns as donkey anaphora that parallel the classic donkey sentences in English. More specifically, the two types of donkey sentences examined in this study include conditional donkey sentences and relative-clause donkey sentences, as in examples (15) and (16) respectively, in which bare nouns are used as indefinite antecedents. The Mandarin conditional donkey sentence in (15) containing the donkey pronoun $t a$ 'it' is analogous to a typical conditional donkey sentence in English. The same parallel is also observed in Mandarin and English relative-clause donkey sentences. In (16), mei-NP is a universal quantifier in Mandarin. Being a universal quantificational determiner, mei is left downward monotone and right upward monotone, as its English counterpart 'every'. In general, the Mandarin donkey sentences used in this study parallel classic donkey sentences, and thus the obtained results can be extended cross-linguistically.
} 


\subsection{Participants}

Twenty-seven monolingual Mandarin-speaking five-year-olds (age range 5;4-5;11, mean 5;7) and 17 Mandarin-speaking adults (age range 20-28, mean 26) participated in Experiment 1. Among the 27 child participants, two had difficulty understanding relative clauses which was crucial for understanding relative-clause donkey sentences, and thus were excluded from the final analysis; an additional two children could not make plausible justifications for their responses on all the eight trials, and thus were eliminated from the final analysis. The remaining 23 children correctly justified their responses on at least six out of eight trials, and therefore were included in the final results. The child participants were recruited from the Beijing Taolifangyuan Kindergarten, and they had no reported history of speech, hearing or language disorders. The adult participants were recruited as controls and were students at Tsinghua University. They were recruited online and had no self-reported speech or hearing disorders.

\subsection{Procedures}

The child participants were tested using a modified Truth Value Judgment task (Crain \& Thornton 1998), where one experimenter acted out stories using toy props and one played the role of a puppet. The task was a slightly modified version of the standard Truth Value Judgment task in that we made the puppet blindfolded, so that he could not see what really happened in the story. This maneuver was used to create a felicity condition on the use of conditionals, namely the uncertainty condition ${ }^{13}$ (Crain et al. 1996). To some extent, conditionals specify hypothetical and uncertain situations. Thus, for the puppet to produce the conditional test sentence felicitously, he must be blind-folded and make a guess at the beginning of each story. In the task, first, the experimenter who acted out the stories introduced each character involved in the story. At the beginning of each story, the experimenter asked the puppet to make a guess about what would happen in the story using a test sentence. When the story concluded, the puppet would repeat the guess, and the child was asked to judge whether or not the puppet had guessed correctly about the story. If the child participants judged that the puppet had made a wrong guess, then they were asked to justify their judgment by telling the puppet "What really happened in the story?".

The 17 adults were tested using a videotaped version of the same task in which the same two experimenters acted out the same stories that were presented to the child participants. At the end of the story, the participants were also asked to judge whether or not the puppet had made a correct guess about the story and they were asked to justify their responses whenever they judged the puppet to be wrong.

\footnotetext{
${ }^{13}$ In child language research, it is a standard practice to adopt the uncertainty mode when investigating children's understanding of conditionals and disjunctions. The use of the uncertainty mode is to satisfy the pragmatic and situational requirement on the use of conditionals and disjunctions. We are following this experimental standard to design the experiment procedure.
} 
Both the child and adult participants were introduced to the task individually and then tested individually. Before the actual test session, they were given one warm-up session, in which the puppet made simple guesses about stories. This warm-up session was used to familiarize the participants with the task.

\subsection{Materials and Design}

Two types of test sentences were created: conditional donkey sentences, as in (15), and relativeclause donkey sentences, as in (16). Four stories were constructed for each sentence type, and in all the four stories only the existential reading of the donkey pronouns corresponds to a "true" response. In addition, the predicates in the main clause of the test sentences had two features, first, they were neither total predicates nor partial predicates, thus controlling for the effect of lexical semantics on the interpretational bias towards either an existential or a universal reading; and second, none of them were collective predicates since the co-occurrence of donkey pronouns and collective predicates would cause the ungrammaticality of the sentence, as discussed in sentence (13).

(15) Ruguo nongfu yang-le gou, ta jiu dai ta qu-le gongyuan.

if farmer raise-ASP dog he then take it go-ASP park

'If a farmer owned a dog, he took it to the park.'

(16) Mei-ge jian-le tangguo de yang dou ba ta huangei-le huitailang.

every-CL pick-ASP candy DE goat all BA it return-ASP Wolffy

'Every goat who picked up a candy gave it back to Wolffy.'

An example story corresponding to the relative-clause donkey sentence in (16) is given as follows. This story was about four goats in a village: Pleasant Goat, Pretty Goat, Athletic Goat and Lazy Goat. There was a bad guy called Wolffy, ${ }^{14}$ who lived near the village. One day, Wolffy bought some candies for his son, Little Grey. He put all the candies in a bag, but didn't notice that the bag was actually broken. On his way home, the candies fell out of the bag. When Wolffy realized, nothing was left in the bag and all the candies were gone. The four goats were playing in a park and then saw candies on the road near the park. Pleasant Goat, Pretty Goat and Athletic Goat, each picked up two candies from the road. Lazy Goat didn't get one, because he was too slow and by the time he got to the road, the other three goats had taken all the candies. Just when the three goats were about to eat the candies, Wolffy saw them with his candies and stopped

\footnotetext{
${ }^{14}$ For readers who are not familiar with the names of the characters, we would like to point out that the five characters (Pleasant Goat, Pretty Goat, Athletic Goat, Lazy Goat and Wolffy) are from a Chinese animated series called Pleasant Goat and Wolffy.
} 
them. He asked the goats to return the candies to him, because these candies were for his son, Little Grey. Pleasant Goat, Pretty Goat and Athletic Goat knew that Wolffy was a bad guy, so they didn't want to return the candies to him. Lazy Goat then told the other three goats that Wolffy's son, Little Grey, was his friend, and they should return the candies to Wolffy. The three goats thought about this for a minute, and then agreed to give the candies back to Wolffy. But the candies smelled so good, and they couldn't resist the temptation of keeping some of these candies for themselves. So, in the end each of the three goats kept one candy and returned the other one to Wolffy. The end scene of the story is illustrated in Figure 1.

We wish to note one important design feature that is associated with the felicity condition on the use of relative clauses. According to Hamburger and Crain (1982), relative clauses are used to restrict from a set. Consider, for example, the relative clause The goat kissed the zebra that jumped over the fence. When uttered in a context, the sentence comes with a presupposition that there were at least two zebras in the conversational context and only one jumped over the fence. As Hamburger and Crain (1982) showed in their study, for children to correctly understand relative clauses, it is crucial to satisfy this presupposition in the context. To do this, we included in the stories an extra character that performed differently from the other characters. In the example story, Lazy Goat was this extra character, and he was contrasted with the other three goats in that he didn't get any candies.

In addition to a test sentence, a filler sentence was added to each story. In the stories testing conditional donkey sentences, simple sentences with numeral constructions were used

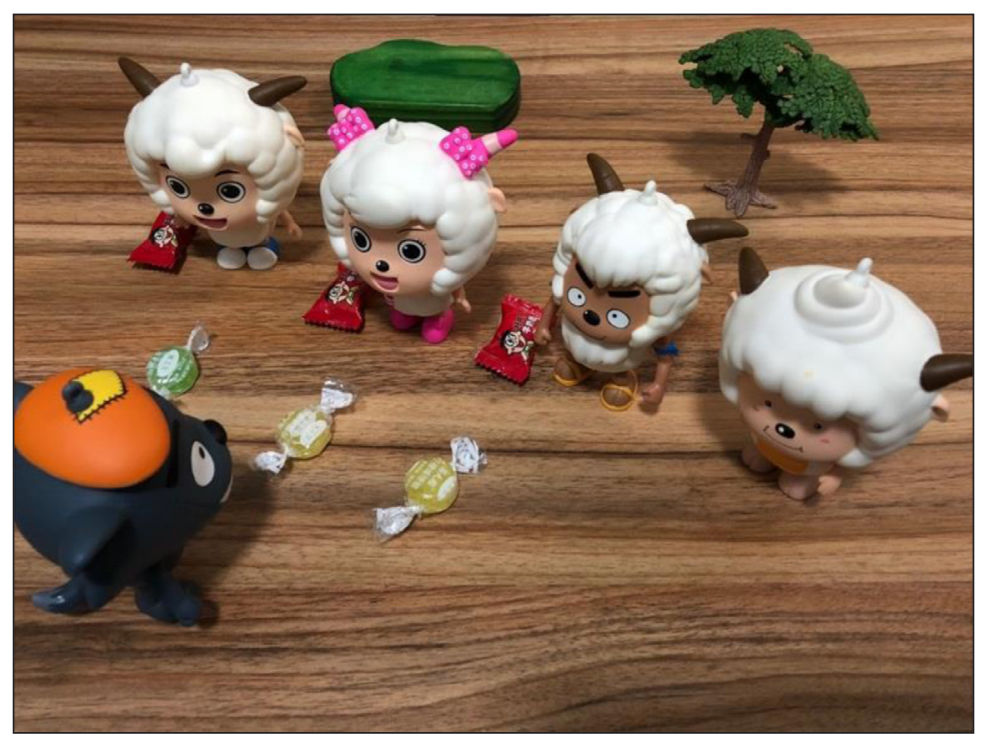

Figure 1: Final scene of the example story. 
as filler sentences, and these sentences were apparently true or false in the given stories. In the stories examining relative-clause donkey sentences, the filler sentences contained the universal quantifier mei...dou... "every...all..." to ensure that the universal quantifier wouldn't pose any difficulties for children to understand relative-clause donkey sentences. ${ }^{15}$

The experiment adopted a within-participants design. All the participants heard eight stories each containing a test and a filler sentence. More specifically, each participant was presented with 4 conditional donkey sentences, 4 relative-clause donkey sentences, 4 simple numeral constructions and 4 simple universally quantified sentences. If the child participants had answered "yes" to a given test sentence produced by the puppet (i.e., they judged that the puppet had made a correct guess), the experimenter who played the role of the puppet was then instructed to use a filler sentence that corresponded to a "no" answer, and vice versa. This ensured that the number of "yes" and "no" responses was balanced throughout the trials. All the test and filler sentences of Experiment 1 are provided in Appendix A in the supplementary file.

\subsection{Predictions}

If the participants assigned an existential reading to the donkey pronoun, they would be expected to judge the test sentences to be true in the given stories; but if they assigned a universal reading to donkey pronouns, they should judge the test sentences to be false in the given stories.

\subsection{Results}

The dependent measure was the acceptance rate of the puppet's statements. Figure 2 gives the mean acceptance rate of the puppet's statements for conditional and relative-clause donkey sentences by Mandarin-speaking children and adults in UE context. As shown in the figure, the 5-year-olds accepted the conditional donkey sentences in the given contexts $96.74 \%$ of the time ( 89 out of 92 trials), and they accepted the relative-clause donkey sentences in the given contexts $80.43 \%$ of the time ( 74 out of 92 trials). By contrast, the adult participants accepted the conditional donkey sentences and the relative-clause donkey sentences in the given contexts only $22.06 \%$ (15 out of 68 trials) and 29.41\% (20 out of 68 trials) of the time respectively.

\footnotetext{
${ }^{15}$ It was found in Philip (1991; 1992; 1995), Roeper and de Villiers (1991) and Takahashi (1991) that Englishspeaking children sometimes assigned a symmetric response to sentences like Is every farmer feeding a donkey? when they were presented with a picture depicting three farmers each are feeding a donkey and there is an extra donkey that is unfed. However, Crain et al. (1996) argued against these previous studies by showing that young children exhibited full grammatical competence of universal quantification when the felicity conditions on the use of universal quantifiers were satisfied in the experimental tasks. In light of this debate, we included mei...dou... 'every...all...' in filler sentences, to make sure that children in our study really understood the universal determiner meige 'every'.
} 


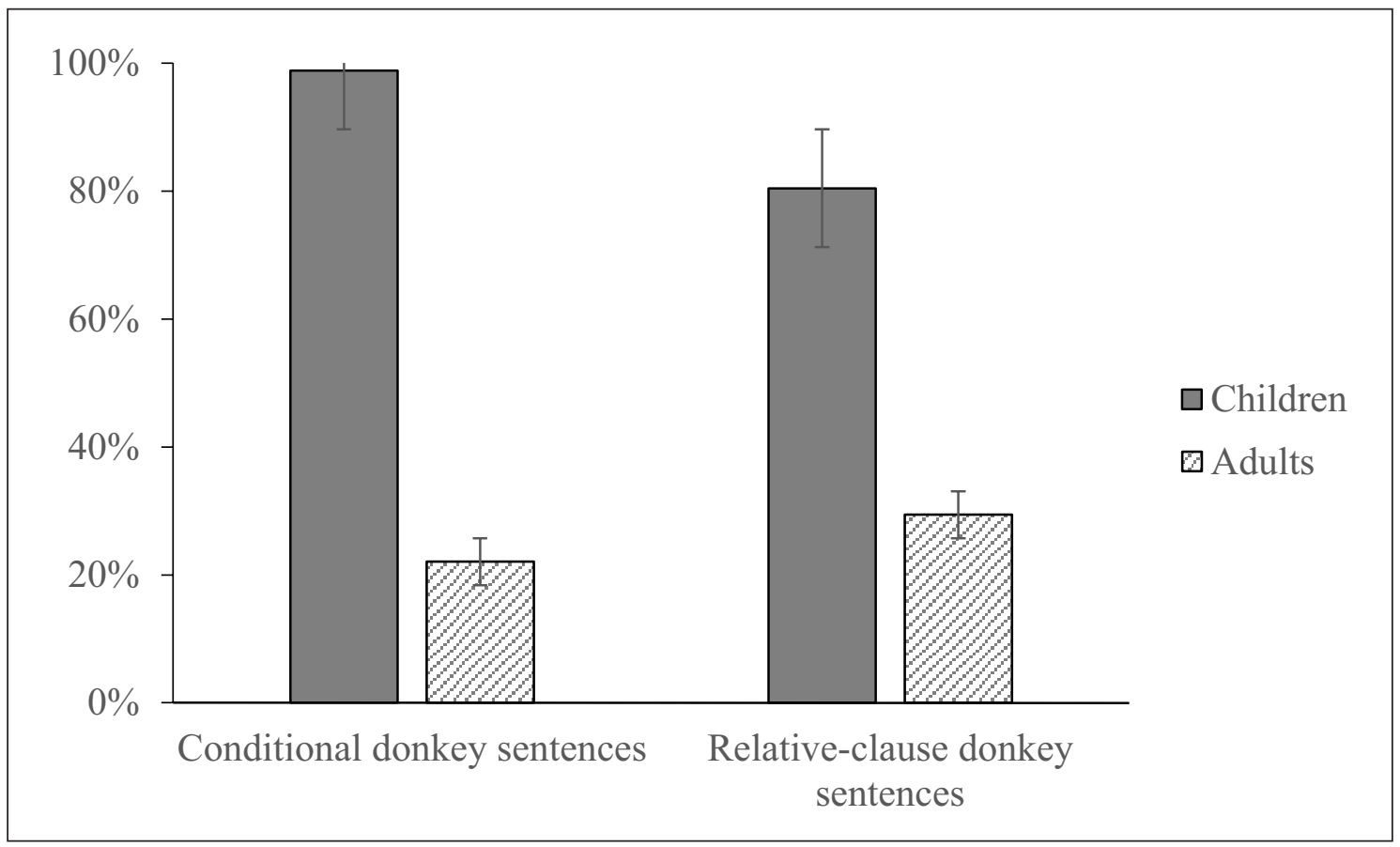

Figure 2: Mean acceptance rates of the conditional and relative-clause donkey sentences by Mandarin-speaking children and adults in UE context; Error bars indicate SEs.

To assess the acceptance rates between the children and the adults statistically, generalized linear mixed models (GLMMs) were applied. We conducted the fitting process via functions lmer from package lme4 (v1.1-12) (Bates, Maechler \& Bolker 2013) of the R (v3.2.5) software environment (R Development Core Team 2017).

We fit the data separately for the acceptance rates in the conditional donkey sentence condition and in the relative-clause donkey sentence condition. In the full model, the fixed effects included the participants' group; the random effects included both items and participants, where both their intercepts and slopes were allowed to vary among all the fixed effects (Baayen et al. 2008; Barr et al. 2013). The full model's complexity was then reduced to see whether the reduced model could explain the same variance as the full model (Bates et al. 2015). If it could, we would accept the simplified model. The final model we used in $\mathrm{R}$ is: acceptance rate $\sim$ group $+(1 \mid$ item $)+(1+$ group $\mid$ item $)$, where age group (i.e., the 5 -year-olds and the adults) was treated as fixed effects, with random intercepts and slopes for items.

The model results revealed that age group was a reliable predictor for the participants' acceptance rates in both conditions. In the conditional donkey sentence condition, the 5-yearolds accepted the sentences significantly more often than the adults did ( $\beta=1.05, S E=0.14$, 
$z=5.26, p<.001)$. In the relative-clause donkey sentence condition, again the 5-year-olds exhibited a significantly higher acceptance rate than the adults $\operatorname{did}(\beta=1.04, S E=0.17, z=$ 4.67, $p<.001$ ).

In addition, generalized linear mixed models were computed to compare the response patterns within each age group. The results showed that the 5-year-olds accepted the conditional donkey sentences significantly more often than they did with the relative-clause donkey sentences ( $\beta=$ 1.03, $S E=0.25, z=2.16, p<.05$ ), whereas the adults tended to reject the two types of donkey sentences equally often. Note that their acceptance rates of the two types of sentences were only $22.06 \%$ and $29.41 \%(\beta=0.20, S E=0.24, z=0.53, p>.05)$.

Note that the participants were asked to justify their responses after they had made judgment about the puppet's statements. The child participants who accepted the donkey sentences either in the form of conditional or relative-clause forms consistently pointed out that the puppet was right, because the characters did satisfy the descriptions by the puppet. By contrast, the participants who rejected the donkey sentences made explicit reference to the fact the characters did not satisfy the descriptions by the puppet. On the example trial, those who accepted the puppet's statement in (16) emphasized that the three goats each returned one candy to Wolffy, and those who rejected the puppet's statement in (16) pointed out that the three goats didn't return all their candies to Wolffy.

The results clearly show that 5-year-old Mandarin-speaking children prefer to interpret donkey pronouns existentially in both conditional and relative-clause donkey sentences, whereas Mandarin-speaking adults strongly favor a universal reading of donkey pronouns in both types of donkey sentences. This discrepancy between children and adults in the interpretation of donkey pronouns in UE contexts parallels the difference between children and adults in the interpretation of English plural definites in UE contexts, as observed in previous research by Caponigro et al. (2012) and Tieu et al. (2019). In addition, as mentioned above Tieu et al. (2019) found that when interpreting plural definites in DE contexts children and adults exhibit similar patterns. This raises an interesting question about children's and adults' interpretation of donkey pronouns in DE contexts: do children and adults interpret donkey pronouns similarly in DE context as they do with plural definites? Experiment 2 was designed to address the question.

\section{Experiment 2}

Experiment 2 examined how Mandarin-speaking children and adults interpreted donkey pronouns in DE contexts, e.g., the nuclear scope of the negative quantified phrase meiyou-renheyige "no one" (morphologically not-any-one since Mandarin does not have a simplex negative quantifier). 


\subsection{Participants}

Twenty-five 5-year-old monolingual Mandarin-speaking children (age range 5;0-5;11, mean 5;6) and 25 Mandarin-speaking adults (age range 20-28, mean 26) participated in Experiment 2. All of the participants' responses were included in the final analysis, because they correctly justified their responses on at least six out of eight trials. The child participants were recruited from Beijing Taolifangyuan Kindergarten, and they had no reported history of speech, hearing or language disorders. The adult participants were students at Tsinghua University. They were recruited online and had no self-reported speech or hearing disorders. None of the participants had participated in Experiment 1.

\subsection{Procedures}

Like in Experiment 1, the child participants were tested using a modified Truth Value Judgment task. The adults were tested using a videotaped version of the same task. The procedures were identical to those in Experiment 1. Both the child and adult participants were introduced to the task individually and then tested individually.

\subsection{Materials and Design}

A within-participant design was adopted in Experiment 2. In this experiment, the participants heard 8 donkey sentences in DE context. The test sentences were all relative-clause donkey sentences containing the negative quantified phrase meiyou-renhe-yige "no one", as in (17). In these sentences, the donkey pronoun occurred in the nuclear scope of the negative quantified phrase, which was a DE context. The filler sentences used the same quantified phrase meiyourenhe-yige "no one" as in the test sentences. An example is given in (18). This was to ensure that the participants understood simple sentences containing the negative quantified phrase. All the test and filler sentences are provided in Appendix B in the supplementary file.

(17) Meiyou renhe yi-ge jian-le tangguo de yang ba ta huangei-le huitailang. not any one-CL pick-ASP candy DE goat BA it return-ASP Wolffy 'No goat who has picked up a candy returned it to Wolffy.'

(18) Meiyou renhe yi-ge yang jiandao-le tangguo.

not any one-CL goat pick-ASP candy

'No goat picked up any candy.'

Two types of story contexts were constructed, which we refer to as Context A and Context B respectively. The details of the two types of contexts can be found in Table 1, where the four goats story was used to illustrate. As noted in the table, in both types of contexts, the universal 


\begin{tabular}{|c|c|c|c|}
\hline Four goats & $\begin{array}{l}\text { Number and } \\
\text { distribution of } \\
\text { candies among } \\
\text { the goats }\end{array}$ & $\begin{array}{l}\text { Number and distribu- } \\
\text { tion of candies that were } \\
\text { returned to Wolffy by the } \\
\text { goats }\end{array}$ & $\begin{array}{l}\text { Number and distribution } \\
\text { of candies that were not } \\
\text { returned to Wolffy }\end{array}$ \\
\hline A & 2 & 0 & 2 \\
\hline B & 2 & 0 & 2 \\
\hline $\mathrm{C}$ & 2 & 1 & 1 \\
\hline $\mathrm{D}$ & 0 & 0 & 0 \\
\hline \multicolumn{4}{|c|}{ Context A-Universal reading: $\mathrm{T} \quad$ Existential reading: $\mathrm{F}$} \\
\hline Four goats & $\begin{array}{l}\text { Number and } \\
\text { distribution of } \\
\text { candies among } \\
\text { the goats }\end{array}$ & $\begin{array}{l}\text { Number and distribu- } \\
\text { tion of candies that were } \\
\text { returned to Wolffy by the } \\
\text { goats }\end{array}$ & $\begin{array}{l}\text { Number and distribution } \\
\text { of candies that were not } \\
\text { returned to Wolffy }\end{array}$ \\
\hline A & 2 & 1 & 1 \\
\hline B & 2 & 1 & 1 \\
\hline $\mathrm{C}$ & 2 & 1 & 1 \\
\hline $\mathrm{D}$ & 0 & 0 & 0 \\
\hline
\end{tabular}

Table 1: Two types of story contexts in Experiment 2.

reading of the test sentences (e.g., (17)) was true and the existential reading of the test sentences was false. ${ }^{16,17}$

${ }^{16}$ The justification of why in these two contexts the universal reading of the donkey pronoun is true and the existential reading is false is that based on the study by Tieu et al. (2019) in which some children interpreted plural definites in negatives existentially but none of them interpreted plural definites universally, we thus expected children to interpret donkey pronouns in downward-entailing contexts existentially. As reported in the literature, children tend to show a yes-response bias when dealing with complex structures, to control for this yes-response bias, we followed the standard procedure in our experimental design to make the expected responses correspond to a False answer (Crain \& Thornton 1998).

17 The two contexts are of no difference in terms of truth conditions. The design of the two contexts were merely for experimental considerations. First, this experimental maneuver was to balance the number of test trials in UE (Exp 1) and DE contexts (Exp 2). Note that there were 8 test stories in UE context. Second, this design was to see whether the number of exceptions influenced children's responses, as discussed in previous research. For example, in Context A there was only one exceptional goat (goat C), but in Context B there were three those goats that don't make the test sentence true (goats A, B and C)(see Table 1). The result of Exp. 2 clearly excluded this possibility given that no significant differences were observed in children's and adults' responses to the two contexts (children: $z=0.88, p>$ .05 ; adults: $z=1.09, p>.05$ ). 


\subsection{Predictions}

If the participants assigned an existential reading to the donkey pronoun in DE context, they would be expected to judge the test sentences to be false in both types of story contexts; but if they assigned a universal reading to donkey pronouns, they should judge the test sentences to be true in the given stories.

\subsection{Results}

The dependent measure was the rejection rate of the puppet's statements. Figure 3 shows the children's and adults' rejection rates of the puppet's statements in the two types of contexts (Context A and Context B) in DE context. As indicated in the figure, the 5-year-olds rejected the donkey sentences in Context A 100\% of the time (100 out of 100 trials) and in Context B 98\% of the time (98 out of 100 trials). Similarly, the adults rejected the donkey sentences in Context A 95\% of the time (95 out of 100 trials) and in Context B 98\% of the time (98 out of 100 trials).

Generalized linear mixed models were applied to compare the rejection rates in the two types of contexts between the children and the adults. We fit the data separately for the rejection rates in Context A and in Context B. We used the same fitting process as in Experiment 1. The best-fitting model treated age group (i.e., the 5-year-olds and the adults) as fixed effects, with random intercepts and slopes for items (Formula in R: rejection rate $\sim$ group $+(1 \mid$ item $)+(1$ + group $($ item)). The model results revealed that there was no significant difference between the

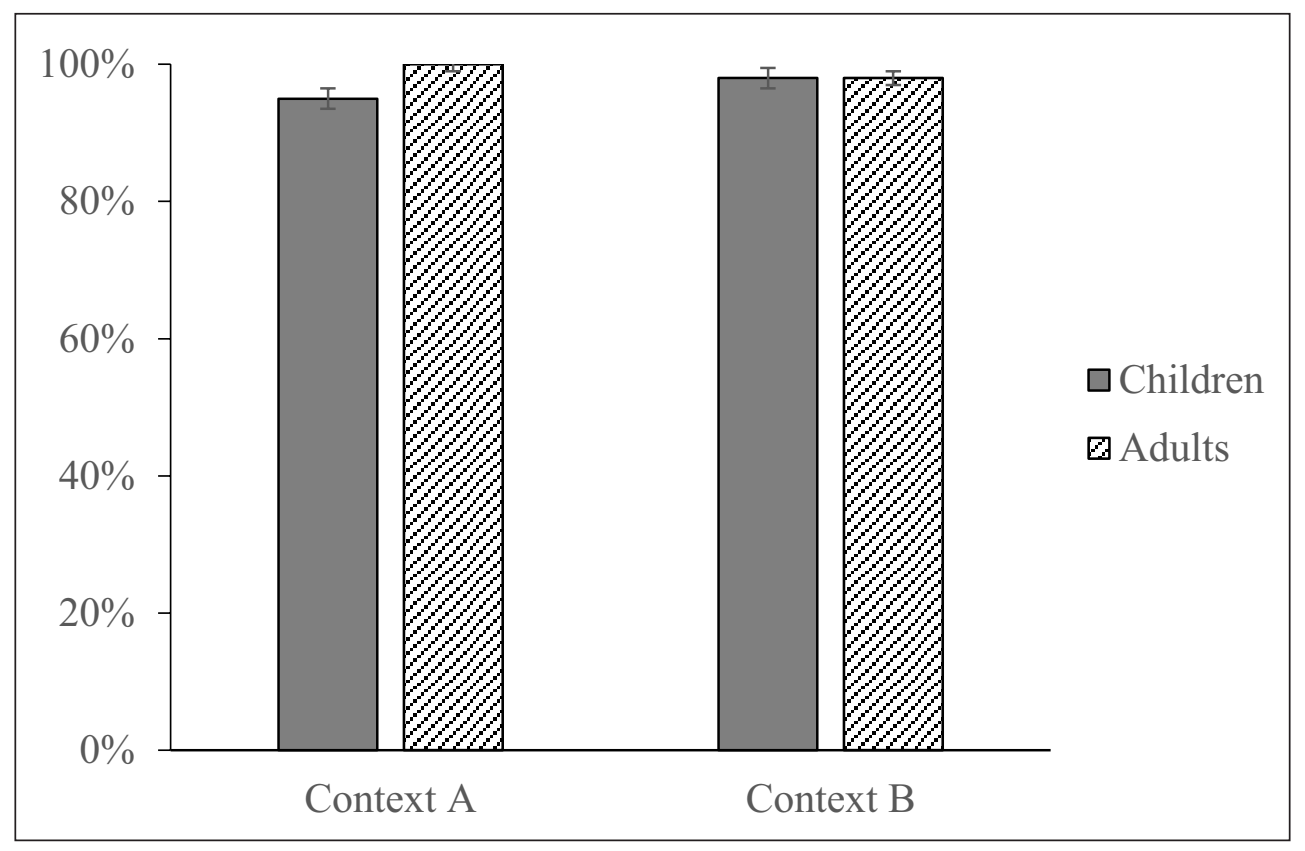

Figure 3: Mean rejection rates of the test sentences in the two types of contexts by Mandarinspeaking children and adults in DE context; Error bars indicate SEs. 
5 -year-olds and the adults in their rejection rates in both two types of contexts (Context A: $\beta=$ $0.06, S E=0.12, z=1.03, p>.05$; Context B: $\beta=0.04, S E=0.23, z=0.87, p>.05$ ).

In addition, generalized linear mixed models were computed to compare the response patterns within each age group. The model results showed the 5-year-olds rejected the donkey sentences in the two types of contexts equally often (95\% vs. $98 \%, \beta=0.11, S E=0.22$, $z=$ $0.88, p>.05)$; so did the adults in the two types of contexts ( $100 \%$ vs. $98 \%, \beta=0.08, S E=$ $0.17, z=1.09, p>.05)$.

Note that the participants were asked to justify their responses after they had made judgment about the puppet's statements, as in Experiment 1. In the example story about the four goats in both types of contexts (see Table 1), the child participants who had rejected the puppet's statement in (17) made explicit reference to the candies that were returned to Wolffy; whereas those who had accepted the puppet's statement in (17) explicitly mentioned the candies that were not returned to Wolffy.

The findings clearly indicate that both Mandarin-speaking children and adults interpret the donkey pronoun existentially in DE contexts.

\section{General discussion}

The present paper sought to investigate young Mandarin-speaking children's interpretation of donkey pronouns in both UE and DE contexts. The findings of Experiment 1 show that in UE contexts Mandarin-speaking children preferred the existential reading of donkey pronouns, whereas Mandarin-speaking adults consistently entertained the universal reading. The results of Experiment 2 demonstrate that in DE contexts both Mandarin-speaking children and adults exhibited a preference for the existential reading of donkey pronouns. Taken together, the findings indicate that young Mandarin-speaking children systematically ${ }^{18}$ interpret donkey pronouns existentially in both UE and DE contexts. The findings provide a cross-linguistic perspective on children's interpretation of donkey pronouns. Our findings, in conjunction with previous research, suggest that the existential reading is perhaps the basic semantics of donkey pronouns.

In addition, as discussed, most prior research on children's understanding of plural definites showed that young children exhibited a strong tendency to assign an existential reading to plural definites in both UE and DE contexts (Karmiloff-Smith 1981; Caponigro et al. 2012; Tieu et al. 2019). The current findings, in conjunction with prior research, provide evidence for the unified

\footnotetext{
${ }^{18}$ By 'systematically' we mean that statistically speaking there is a consistent pattern in children's performance that they interpret donkey pronouns in UE and DE contexts existentially. Although in UE contexts approximately $20 \%$ of the time children give the universal interpretation, statistically speaking $20 \%$ is an outlier that should have no effect on the consistent pattern.
} 
analysis of donkey pronouns and plural definites by Krifka (1996) and Yoon (1996), which we also follow in our treatment of donkey pronouns in the current paper.

Specifically, we propose that donkey pronouns are numberless definites, and give rise to an $\exists$-interpretation as the basic meaning when combined with their predicates, as in the case of predication over plural definites which exhibits homogeneity. The basic $\exists$-reading can, however, be strengthened, via a mechanism that is now commonly employed to generate different types of implicatures (Chierchia et al. 2012), and this delivers the $\forall$-reading (Magri 2014; Bar-Lev $2018 ; 2020)$. On this proposal, children's initial preference for the existential reading can be well explained. Children start out with the basic semantics and their lack of universal reading in UE contexts is presumably due to their difficulty in implementing the strengthening mechanism or in computing the subdomain alternatives.

Below we offer a concrete implementation of the proposal closely following Bar-Lev's (2018; 2020) recent analysis of homogeneity with plural definites. ${ }^{19}$ In Bar-Lev's analysis of homogeneity, plural definites such as the kids, as in the classical treatment (Sharvy 1980; Link 1983), still denotes the maximal sum of all entities in the KID set as in (19b), and plural predication over the sum is mediated via a distributivity (or pluralization) operator (Link 1987; Schwarzschild 1996). Departing from the previous accounts, Bar-Lev proposes that the distributivity operator has an existential semantics, as in (19c), which renders the $\exists$-reading of plural predication the basic interpretation (which immediately explains children's tendency to interpret plural definites existentially). In other words, simply predicating laughed over the kids gives rise to a weak existential claim that at least one kid laughed as in (19d). Note that the subscript $D$ represents the domain of quantification of the distributivity operator, and is taken to be the latter's domain argument (von Fintel 1994).

(19) The kids laughed.

a. Basic LF: [The kids] $\left[\exists-\mathrm{PL}_{D}\right.$ laughed]

b. $\llbracket$ the kids $\rrbracket=\oplus$ KID

c. $\llbracket \exists-\mathrm{PL} \rrbracket=\lambda D_{e t} \cdot \lambda P_{e t} \cdot \lambda x_{e} \cdot \exists y\left[y \leq_{\text {Atom }} x \wedge y \in D \wedge P(y)\right]$

d. $\llbracket\left[\right.$ The kids $\rrbracket\left[\exists-\mathrm{PL}_{D}\right.$ laughed $] \rrbracket=1$ iff $\exists y\left[y \leq_{\text {Atom }} \oplus \operatorname{KID} \wedge y \in D \wedge \operatorname{LAUGHED}(y)\right]$

e. $\operatorname{Alt}((18 \mathrm{a}))=\left\{[\right.$ The kids $]\left[\exists-\mathrm{PL}_{D^{\prime}}\right.$, laughed $\left.]: D^{\prime} \subseteq D\right\}$

Next, the domain variable $D$ triggers alternatives (as focused expressions do in Rooth 1992). In particular, it triggers sub-domain alternatives $D^{\prime}$ (Chierchia 2013), which are basically sets

19 There are other approaches to homogeneity, such as the Trivalence approach by Schwarzschild (1994), Löbner (2000), Gajewski (2005), Križ (2015; 2016) and the Ambiguity approach by Dalrymple et al. (1994), Križ \& Spector (2021). We follow the Implicature approach (Magri 2014; Bar-Lev 2018; 2020) and in particular Bar-Lev's (2018; 2020) account, since asymmetry (between $\exists$ and $\forall$ ) is highlighted therein and straightforwardly follows from the proposal. 
smaller than $D$. These domain alternatives project to the sentence level and thus we have a set of alternative existential statements whose domain of quantification smaller than the one in the prejacent $D$, which is represented in (19d).

Alternatives, once activated, must be exhaustified. Bar-Lev, following Bar-Lev \& Fox's (2017) analysis of free choice effects (which in turn builds on Kratzer \& Shimoyama 2002 and Fox 2007), proposes that the alternatives such as the ones in (19e) are exhaustified by the operator $E x h^{I E+I I}$, which negates certain alternatives (the Innocently-Excludable/IE ones) and affirms some others (the Innocently-Includable/II ones). The set of IE alternatives is the intersection of all the maximal sets of alternatives whose joint negation is consistent with the sentence that the operator attaches to (the prejacent), formally defined in (20) (Fox 2007). The set of II alternatives on the other hand is the intersection of all of the maximal sets of alternatives that can be assigned true consistent with the prejacent and falsity of all IE alternatives, formally represented in (21). With the definition of IE and II, the exhaustification operator $E x h^{I E+I I}$ simply negates all the IE alternatives and affirms the II ones, as in (22). ${ }^{20}$

(20) Given a sentence $p$ and a set of alternatives $C$ :

$\operatorname{IE}(p, C)=\cap\left\{C^{\prime} \subseteq C: C^{\prime}\right.$ is a maximal subset of $C$, s.t. $\left\{\neg q: q \in C^{\prime}\right\} \cup\{p\}$ is consistent $\}$

(21) Given a sentence $p$ and a set of alternatives $C$ :

$\mathrm{II}(p, C)=\cap\{C ” \subseteq C: C$ ' is a maximal subset of $C$, s.t. $\{\mathrm{r}: \mathrm{r} \in C ’\} \cup\{p\} \cup\{\neg q: q \in I E(p, C)\}$ is consistent\}

$$
\llbracket \operatorname{Exh}^{I E+I I} \rrbracket(C)(p)(w) \Leftrightarrow \forall q \in I E(p, C)[\neg q(w)] \wedge \forall r \in I I(p, C)[r(w)]
$$

To illustrate how the strengthening from $\exists$ to $\forall$ happens, consider the kids laughed in a context with two kids John and Mary. Here the kids denotes JOHN $\bigoplus$ MARY and thus the prejacent of $E x h_{c}^{I++I I}$

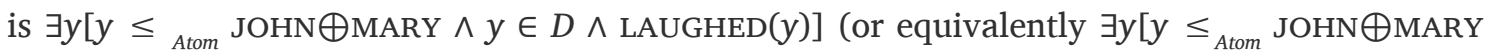
$\wedge$ LAUGHED(y)]) and it has two (non-vacuous) sub-domain alternatives in its alternative set $C$ : LAUGHED(JOHN) and LAUGHED(MARY). Neither is IE (since there are two maximal subsets of $C$ whose joint negation is consistent with the prejacent \{LAUGHED(JOHN)\} and \{LAUGHED(MARY)\}, and their intersection is the empty set), and both are II (both can be assigned true consistent with the prejacent and falsity of all IE alternatives). Consequently, $E x h_{c}^{I E+I I}$ affirms both and the result is $\forall y\left[y \leq_{\text {Atom }}\right.$ JOHN $\bigoplus$ MARY $\wedge$ LAUGHED(y)]. The prejacent is successfully strengthened from an existential statement to a universal one, via alternatives and exhaustification.

\footnotetext{
${ }^{20}$ Intuitively, $E x h^{I E+I I}$ first negates as many alternatives as possible in a non-arbitrary way without causing contradiction (Innocent Exclusion) and then it affirms as many alternatives as possible within the rest alternatives.
} 
(23) The kids laughed.

a. Strengthened LF: $E x h_{c}^{I E+I I}\left[\left[T h e\right.\right.$ kids] $\left[\exists-\mathrm{PL}_{D}\right.$ laughed] $]$

b. Prejacent of $E x h_{c}^{I E+I I}: \exists y\left[y \leq_{A t o m}\right.$ JOHN $\bigoplus$ MARY $\wedge$ LAUGHED $\left.(y)\right]$

c. The set of alternatives C: $\{$ LAUGHED(JOHN), LAUGHED(MARY) $\}$

d. The set of IE alternatives: $\phi$

e. The set of II alternatives: \{LAUGHED(JOHN), LAUGHED(MARY) \}

f. Result of exhaustification: LAUGHED(JOHN) $\wedge$ LAUGHED(MARY) or equivalently $\forall y\left[y \leq_{\text {Atom }}\right.$ JOHN $\bigoplus$ MARY $\left.\rightarrow \operatorname{LAUGHED}(y)\right]$

In general, in the case of predication with plural definites in positive contexts, since all the sub-domain alternatives are innocently-includable and there are no excludable ones, all the alternatives are affirmed to be true, and we thus get the strengthened universal interpretation.

Finally, the analysis predicts that predication with plural definites under negation (and in DE contexts in general) receives the basic existential interpretation. Consider the LF of the kids didn't laugh in (24a) (note that exhaustification usually does not appear embedded under negation, see Chierchia et al. 2012 and Fox \& Spector 2018). It turns out that the exhaustification operator $E x h_{c}^{I E+I I}$ is vacuous, since its prejacent in (24b) entails all of its alternatives in (24c) and is already the strongest (and thus there is no IE alternative, and even though all the alternatives are II, affirming them does not strengthen the prejacent).

(24) The kids didn't laugh.

a. LF: $E x h_{c}^{I E+H}\left[\right.$ Not [[The kids] [ $\exists-\mathrm{PL}_{D}$ laughed]]]

b. Prejacent of $\operatorname{Exh}_{c}^{I++I}: \neg \exists y\left[y \leq_{\text {Atom }} \oplus \operatorname{KID} \wedge \operatorname{LAUGHED}(y)\right]$

c. The set of alternatives C: $\{\neg$ LAUGHED(JOHN), $\neg$ LAUGHED(MARY) $\}$

The above discussion illustrates Bar-Lev's analysis of homogeneity and predication with plural definites. Now we illustrate how Bar-Lev's analysis can be extended to Mandarin donkey pronouns. With the assumption that donkey pronouns are numberless definites (Krifka 1996; Yoon 1996), the LF of (16) (repeated here as (25)) is given in (26). In (26), the donkey pronoun ta is interpreted as a numberless definite the candy(s) he picked up, when combined with its predicate it gives rise to an existential semantics, indicated by the $\exists-\mathrm{PL}_{D}$ in (26). It also triggers sub-domain alternatives as in Bar-Lev's analysis of plural definites. These alternatives call for exhaustification, and thus we have the presence of $E x h_{c}^{I E+I I}$ in (26). We assume that $E x h_{c}^{I E+I I}$ applies in the nuclear scope of every, since the donkey pronoun resides in the nuclear scope of every which is a UE context so that $E x h_{c}^{I E+I I}$ can (or must) apply. The similar embedded strengthening can be seen in the derivation of universal free choice (Chemla 2009; Chierchia et al. 2012; Singh et al. 2016). As the reader can verify, this delivers the correct result. Just as in Bar-Lev's analysis, $E x h_{c}^{I E+I I}$ strengthens the basic existential interpretation to a universal one, as illustrated above in (23). 
(25) Mei-ge jian-le tangguo de yang dou ba ta huangei-le huitailang. every-CL pick-ASP candy DE goat all BA it return-ASP Wolffy

'Every goat who picked up a candy gave it back to Wolffy.'

(26) [Every goat who picked up a candy $]_{2}\left[\lambda 2 \operatorname{Exh}_{c}^{I E+I I}\left[\left[\text { the candy(s) he }{ }_{2} \text { picked up }\right]_{1} \exists-\mathrm{PL}_{D}\right.\right.$ $\left[\lambda 1\left[t_{2}\right.\right.$ gave $t_{1}$ back to Wolffy] $\left.]\right]$

When it comes to the donkey pronoun in the downward entailing environment, take (17) as an example, now repeat as (27), where meiyou-renhe 'not any' in Mandarin is similar to the English negative quantifier none. Since the non-existence statement is already the strongest, the matrix exhaustification operator in (27b) is vacuous. Thus in negative environment what is revealed is the basic semantics of donkey pronoun. The donkey sentence in (27a) is true if and only if there doesn't exist a man who owns any donkey and beats any of his donkey(s) he owns. Note that embedding $E x h_{c}^{I E+I I}$ under negation is generally prohibited (Chierchia et al. 2012; Fox \& Spector 2018), and in the case of donkey sentences as in (27) the indefinite 'a candy' conveys the meaning 'any candy' which is already the strongest and thus $E x h_{c}^{I E+I I}$ would not apply within the scope of negation, because typically implicatures cannot be embedded under DE operators unless the relevant scalar term bears pitch accent (Fox \& Spector 2018). Thus [None of the goats who picked up a candy $]_{2}\left[\lambda 2 \operatorname{Exh}_{c}^{I E+I I}[\text { the candy(s) he picked up }]_{1} \exists-\mathrm{PL}_{D}\left[\lambda 1\left[t_{2}\right.\right.\right.$ gave $t_{1}$ back to Wolffy]]] is not a viable LF.

(27) a. Meiyou renhe yi-ge jian-le tangguo de yang ba ta huangei-le huitailang. not any one-CL pick-ASP candy DE goat BA it return-ASP Wolffy 'No goat who has picked up a candy returned it to Wolffy.'

b. $E x h_{c}^{I E+I I}[\text { None of the goats who picked up a candy }]_{2}\left[\lambda 2\left[\left[\right.\right.\right.$ the candy(s) he ${ }_{2}$ picked up $]_{1} \exists-\mathrm{PL}_{D}\left[\lambda 1\left[t_{2}\right.\right.$ gave $t_{1}$ back to Wolffy $\left.\left.\left.]\right]\right]\right]$

This proposal explains nicely children's initial preference for the existential reading of donkey pronouns and plural definites. This preference in UE contexts is presumably due to their difficulty in implementing the strengthening mechanism that turns $\exists$ to $\forall$ or in computing subdomain alternatives. More specifically, in UE contexts, adults can effectively compute the subdomain alternatives and perform the strengthening mechanism, and therefore successfully arrive at the $\forall$-reading, whereas young children fail to do so, and thus initially assign the basic $\exists$-reading (Experiment 1). This failure might be attributed to children's difficulty in computing subdomain alternatives or in implementing the strengthening mechanism. First, in the former case, the alternatives are not explicitly provided as substrings of the assertion in the donkey sentences, which stands in contrast with the case in free choice inference (Tieu et al. 2016). Prior studies have shown that children can benefit from the explicitly mentioned alternatives in computing 
the corresponding inferences, which seem to provide evidence for the former case (Chierchia et al. 2001; Gualmini et al. 2001; Reinhart 2006; Tieu et al. 2016). In addition, Singh et al. (2016) argued that children's difficulty in computing implicatures is probably due to their limited access to the lexicon associated with alternatives, e.g., children might only have a proper subset of the adult alternatives. Based on these previous studies, we assume that children's difficulty was due to that the subdomain alternatives were not explicitly given in the test sentence. Second, turning to the strengthening mechanism, although Singh et al. (2016) proposed that children have adult-like capacity to implement strengthening mechanism when deriving implicatures, the findings of the current study did not allow us to disentangle the two possibilities, i.e., difficulty in implementing the strengthening mechanism or in computing subdomain alternatives. The exploration of the two possibilities requires further research.

We also wish to note that in DE contexts where negation takes scope over the existential quantifier, the not existential reading is already the strongest reading and thus it's unnecessary to implement the strengthening mechanism. What's more, it's vacuous to apply the strengthening mechanism in the matrix level and as usual with implicatures deriving them below negation is generally prohibited, as schematically represented in (27). This explains why both children and adults exhibit initial preference for the existential reading of donkey pronouns in DE contexts.

\section{Conclusions}

To conclude, the parallels between donkey pronouns and plural definites with respect to monotocity, lexical semantics of the predicate with which they are combined, and the discourse context in which they occur led to a unified theoretical analysis of the two elements. The present study provided further evidence for the unified analysis by turning to child language acquisition. The major findings were that Mandarin-speaking children favored the existential reading for donkey pronouns whereas the adults preferred the universal reading for donkey pronouns in UE contexts; by contrast, both the children and the adults exhibited similar patterns in DE contexts, favoring the existential reading of donkey pronouns. On the basis of the findings, we propose that the basic semantics of donkey pronouns is existential when it combines with the predicate, and the universal reading is derived through a strengthening mechanism as implemented in BarLev (2020). The experimental results indicate that children may have difficulty in implementing the strengthening mechanism or in computing subdomain alternatives. 


\section{Abbreviations}

$\exists=$ existential, $\forall=$ universal, $\mathrm{NP}=$ noun phrase, QDet $=$ quantificational determiner, $\mathrm{UE}=$ upward entailing, $\mathrm{DE}=$ downward entailing, $\mathrm{CL}=$ classifier, ASP $=$ aspect, $\mathrm{II}=$ innocently includable, IE = innocently excludable, $\mathrm{PL}=$ plural, $\mathrm{LF}=$ logical form

\section{Additional File}

The additional file for this article can be found as follows:

- Supplementary file 1. Appendices. DOI: http://doi.org/10.16995/glossa.5710.s36

\section{Ethics and Consent}

The study was approved by the Ethics Committee of the School of Medicine, Tsinghua University, 20170018. Written informed consent has been obtained from each child participants' parents and each adult participant.

\section{Acknowledgements}

The authors would like to thank the children, the parents and the teachers at the Taolifangyuan Kindergarten, and the adult participants at Tsinghua University, Beijing, China, for their assistance and support in running the study. The authors are also grateful to the anonymous reviewers for their insightful comments and suggestions on earlier versions of the manuscript.

\section{Funding Information}

This research was supported by the National Natural Science Foundation of China (No. U20B2062) to PZ.

\section{Competing Interests}

The authors have no competing interests to declare.

\section{Author Contributions}

The three authors contributed equally to this work. 


\section{References}

Baayen, Harald R. \& Davidson, Douglas J. \& Bates, Douglas M. 2008. Mixed-effects modeling with crossed random effects for subjects and items. Journal of Memory and Language 59. 390-412. DOI: https://doi.org/10.1016/j.jml.2007.12.005

Bar-Lev, Moshe E. 2018. Free choice, homogeneity, and innocent inclusion. Jerusalem: Hebrew University of Jerusalem dissertation.

Bar-Lev, Moshe E. 2020. An implicature account of homogeneity and non-maximality. Linguistics and Philosophy. (Accessed 15-09-2020). DOI: https://doi.org/10.1007/s10988-02009308-5

Bar-Lev, Moshe E. \& Fox, Danny. 2017. Universal free choice and innocent inclusion. In Burgdorf, Dan \& Collard, Jacob \& Maspong, Sireemas \& Stefánsdóttir, Brynhildur (eds.), Proceedings of Semantics and Linguistic Theory (SALT) 27. 95-115. Ithaca, New York: CLC Publications. DOI: https://doi.org/10.3765/salt.v27i0.4133

Barr, Dale J. \& Levy, Roger \& Scheepers, Christoph \& Tily, Harry J. 2013. Random effects structure for confirmatory hypothesis testing: Keep it maximal. Journal of Memory and Language 68. 255-278. DOI: https://doi.org/10.1016/j.jml.2012.11.001

Bates, Douglas M. \& Kliegl, Reinhold \& Vasishth, Shravan \& Baayen, Harald R. 2015. Parsimonious mixed models. Retrieved from arXiv: 1506.04967 (stat.ME).

Bates, Douglas M. \& Maechler, Martin \& Bolker, Benjamin. 2013. lme4: Linear mixed-effects models using S4 classes. Retrieved from http://cran.r-project.org/web/packages/lme4/index.html.

Brasoveanu, Adrian. 2008. Donkey pluralities: plural information states versus non-atomic individuals. Linguistics and Philosophy 31. 129-209. DOI: https://doi.org/10.1007/s10988-0089035-0

Caponigro, Ivano \& Pearl, Lisa \& Brooks, Neon \& Barner, David. 2010. On the acquisition of maximality in free relative clauses and plural definite descriptions. In Li, Nan \& Lutz, David (eds.), Proceedings of Semantics and Linguistic Theory (SALT) 20. 508-524. Ithaca, New York: CLC Publications. DOI: https://doi.org/10.3765/salt.v20i0.2564

Caponigro, Ivano \& Pearl, Lisa \& Brooks, Neon \& Barner, David. 2012. Acquiring the meaning of free relative clauses and plural definite descriptions. Journal of Semantics 29(2). 261-293. DOI: https://doi.org/10.1093/jos/ffr014

Champollion, Lucas \& Bumford, Dylan \& Henderson, Robert. 2019. Donkeys under discussion. Semantics and Pragmatics 12(1). 1-50. DOI: https://doi.org/10.3765/sp.12.1

Chemla, Emmanuel. 2009. Universal implicatures and free choice effects: Experimental data. Semantics and Pragmatics 2(2). 1-33. DOI: https://doi.org/10.3765/sp.2.2

Cheng, Lisa L.-S. \& Huang, C.-T. James. 1996. Two types of donkey sentences. Natural Language and Philosophy 15. 111-183. DOI: https://doi.org/10.1007/BF00355411

Cheng, Lisa L.-S. \& Huang, C.-T. James. 2020. Revisiting donkey anaphora in Mandarin Chinese: A reply to Pan and Jiang (2015). International Journal of Chinese Linguistics 7(2). 167-186. DOI: https://doi.org/10.1075/ijchl.19020.che 
Chierchia, Gennaro. 1992. Anaphora and dynamic binding. Linguistics and Philosophy 15(2). 111183. DOI: https://doi.org/10.1007/BF00635805

Chierchia, Gennaro. 1995. Dynamics of meaning: anaphora, presupposition, and the theory of grammar. Chicago and London: The University of Chicago Press. DOI: https://doi.org/10.1016/08981221(95)90239-2

Chierchia, Gennaro. 2000. Chinese conditional and the theory of conditionals. Journal of East Asian Linguistics 9. 1-54. DOI: https://doi.org/10.1023/A:1008317108361

Chierchia, Gennaro. 2013. Logic in grammar. Oxford: Oxford University Press. DOI: https://doi. org/10.1093/acprof:oso/9780199697977.001.0001

Chierchia, Gennaro. 2020. Homogeneity, scopeless and discourse dynamics. Handout, LINGUAE Seminar.

Chierchia, Gennaro \& Fox, Danny \& Spector, Benjamin. 2012. Scalar implicature as a grammatical phenomenon. In Maienborn, Claudia \& von Heusinger, Klaus \& Portner, Paul (eds.), Semantics: An international handbook of natural language meaning 3. 2297-2331. Berlin: Mouton de Gruyter. DOI: https://doi.org/10.1515/9783110253382.2297

Conway, Laura \& Crain, Stephen. 1995a. Donkey anaphora in child grammar. In Beckman, Jill N. (ed.), Proceedings of The Meeting of the North East Linguistics Society (NELS) 25. 30-46. Amherst, Mass: GLSA, University of Massachusetts. Available at: https://scholarworks.umass.edu/nels/ vol25/iss $1 / 4$

Conway, Laura \& Crain, Stephen. 1995b. Dynamic acquisition. In MacLaugnlin, Dawn \& McEwen, Susan (eds.), Proceedings of the $19^{\text {th }}$ Annual Boston University Conference on Language Development (BUCLD 19), 180-191. Somerville, MA: Cascadilla Press.

Cooper, Robin. 1979. The interpretation of pronouns. In Heny, Frank \& Schnelle, Helmut S. (eds.), Syntax and Semantics: Selections from the Third Groningen Round Table 10. 61-92. New York: Academic Press. DOI: https://doi.org/10.1163/9789004373082_004

Crain, Stephen \& Thornton, Rosalind. 1998. Investigations in universal grammar: A guide to experiments on the acquisition of syntax and semantics. Cambridge, MA: The MIT Press.

Crain, Stephen \& Thornton, Rosalind \& Boster, Carole \& Conway, Laura \& Lillo-Martin, Diane \& Woodams, Elaine. 1996. Quantification without qualification. Language Acquisition 5(2). 83-153. DOI: https://doi.org/10.1207/s15327817la0502_2

Dalrymple, Mary \& Kanazawa, Makoto \& Mchombo, Sam \& Peters, Stanley. 1994. What do reciprocals mean? In Harvey, Mandy \& Santelmann, Lynn (eds.), Proceedings of Semantics and Linguistics Theory (SALT) 4. 61-78. Ithaca, New York: CLC Publications. DOI: https://doi. org/10.3765/salt.v4i0.2466

Davies, Martin. 1981. Meaning, quantification, necessity. London, Boston and Henley: Routledge \& Kegan Paul. DOI: https://doi.org/10.4324/9780367853952

Evans, Gareth. 1977. Pronouns, quantifiers and relative clauses. Canada Journal of Philosophy 8. 467-536. DOI: https://doi.org/10.1080/00455091.1977.10717030

Evans, Gareth. 1980. Pronouns. Linguistic Inquiry 11(2). 337-362. 
Fox, Danny. 2007. Free choice and the theory of scalar implicatures. In Sauerland, Uli \& Stateva, Penka (eds.), Presupposition and implicature in compositional semantics, 71-120. New York: Palgrave Macmillan. DOI: https://doi.org/10.1057/9780230210752_4

Fox, Danny \& Spector, Benjamin. 2018. Economy and embedded exhaustification. Natural Language Semantics 26. 1-50. DOI: https://doi.org/10.1007/s11050-017-9139-6

Gajewski, Jon Robert. 2005. Neg-raising: Polarity and presupposition. MA: Massachusetts Institute of Technology dissertation.

Gawron, Jean M. \& Nerbonne, John \& Stanley, Peters. 1991. The absorption principle and E-type anaphora. In Barwise, Jon \& Gawron, Jean Mark \& Plotkin, Gordon \& Tutiya, Syun (eds.), Situation Theory and its Applications 2. 335-362. Stanford: CSLI Publications.

Geach, Peter T. 1962. Reference and generality: An examination of some medieval and modern theories. Ithaca, New York: Cornell University Press.

Geurts, Bart. 2002. Donkey business. Linguistic and Philosophy 25(2). 129-156. DOI: https://doi. org/10.1023/A:1014624331450

Groenendijk, Jeroen \& Stokhof, Martin. 1991. Dynamic predicate logic. Linguistics and Philosophy 14. 39-100. DOI: https://doi.org/10.1007/BF00628304

Hamburger, Henry \& Crain, Stephen. 1982. Relative acquisition. In Kuczaj, Stan (ed.), Language development: Syntax and semantics, 245-274. Hillsdale, NJ: Erlbaum.

Heim, Irene. 1982. The semantics of definite and indefinite noun phrases. Amherst: University of Massachusetts dissertation.

Heim, Irene. 1990. E-type pronouns and donkey anaphora. Linguistics and Philosophy 13. 137179. DOI: https://doi.org/10.1007/BF00630732

Kamp, Hans. 1981. A theory of truth and semantic representation. In Groenendijk, Jeroen \& Janssen, Theo \& Stokhof, Martin (eds.), Formal Methods in the Study of Language: Proceedings of the Third Amsterdam Colloquium 1. 227-321. Amsterdam: Mathematical Center. DOI: https://doi. org/10.1515/9783110867602.1

Kanazawa, Makoto. 1994. Weak and strong readings of donkey sentences and monotonicity inferences in a dynamic setting. Linguistics \& Philosophy 17. 109-158. DOI: https://doi. org/10.1007/BF00984775

Kanazawa, Makoto. 2001. Singular donkey pronouns are semantically singular. Linguistics and Philosophy 24(3). 383-403. DOI: https://doi.org/10.1023/A:1010766724907

Karmiloff-Smith, Annette. 1981. A functional approach to child language: A study of determiners and reference. Cambridge: Cambridge University Press.

Kratzer, Angelika \& Shimoyama, Junko. 2002. Indeterminate pronouns: The view from Japanese. In Otsu, Yukio (ed.), The Proceedings of the Third Tokyo Conference on Psycholinguistics, 1-25. Tokyo: Hituzi Syobo. DOI: https://doi.org/10.1007/978-3-319-10106-4_7

Krifka, Manfred. 1996. Pragmatic strengthening in plural predications and donkey sentences. In Galloway, Teresa \& Spence, Justin (eds.), Proceedings of Semantics and Linguistic Theory (SALT) 6. 136-153. Ithaca, New York: CLC Publications. DOI: https://doi.org/10.3765/salt.v6i0.2769 
Križ, Manuel. 2015. Aspects of homogeneity in the semantics of natural language. Vienna: University of Vienna dissertation. Available at: https://manuel.kriz.fr/wp-content/uploads/Kriz_2015_ Aspects_of_Homogeneity.pdf

Križ, Manuel. 2016. Homogeneity, non-maximality, and all. Journal of Semantics 33. 1-47. DOI: https://doi.org/10.1093/jos/ffv006

Križ, Manuel \& Benjamin Spector. 2021. Interpreting plural predication: homogeneity and non-maximality. Linguistics and Philosophy. (Accessed from 03-11-2020) DOI: https://doi. org/10.1007/s10988-020-09311-w

Lappin, Shalom. 1989. Donkey pronouns unbound. Theoretical Linguistics 15. 263-289. DOI: https://doi.org/10.1515/thli.1988.15.3.263

Lappin, Shalom, \& Francez, Nissim. 1994. E-type pronouns, I-sums, and donkey anaphora. Linguistics and Philosophy 17. 391-428. DOI: https://doi.org/10.1007/BF00985574

Lewis, David. 1975. Adverbs of quantification. In Keenan, Edward L. (ed.), Formal semantics of natural language, 3-15. Cambridge: Cambridge University Press. DOI: https://doi.org/10.1017/ СBO9780511897696.003

Link, Godehard. 1983. The logical analysis of plurals and mass terms: A lattice-theoretic approach. In Bäuerle, Rainer \& Schwarze, Christoph \& von Stechow, Arnim (eds.), Meaning, use and interpretation of language, 302-323. Berlin: de Gruyter. DOI: https://doi.org/10.1515/978311085 2820.302

Link, Godehard. 1987. Generalized quantifiers and plurals. In Gärdenfors, Peter (ed.), Generalized quantifiers: Linguistic and logical approaches, 151-180. Dordrecht: Kluwer. DOI: https://doi. org/10.1007/978-94-009-3381-1_6

Löbner, Sebastian. 1987. Quantification as a major module of natural language semantics. In Groenendijk, Jeroen A. G. \& de Jongh, Dick \& Sttokhof, Martin J. B. (eds.), Studies in discourse representation theory and the theory of generalized quantifiers, 53-85. Dordrecht: Foris. DOI: https:// doi.org/10.1515/9783112420027-004

Löbner, Sebastian. 2000. Polarity in natural language: predication, quantification and negation in particular and characterizing sentences. Linguistics and Philosophy 23(3). 213-308. DOI: https:// doi.org/10.1023/A:1005571202592

Magri, Giorgio. 2014. An account for the homogeneity effects triggered by plural definites and conjunction based on double strengthening. In Pistoia-Reda, Salvatore (ed.), Pragmatics, semantics and the case of scalar implicatures, 99-145. UK: Palgrave Macmillan. DOI: https://doi. org/10.1057/9781137333285_5

Malamud, Sophia A. 2012. The meaning of plural definites: A decision-theoretic approach. Semantics and Pragmatics 5(3). 1-58. DOI: https://doi.org/10.3765/sp.5.3

Munn, Alan \& Miller, Karen \& Schmitt, Cristina. 2006. Maximality and plurality in children's interpretation of definites. In Bamman, David \& Magnitskaia, Tatiana \& Zaller, Colleen (eds.), Proceedings of the $30^{\text {th }}$ Annual Boston University Conference on Language Development (BUCLD 30), 377-387. Somerville, MA: Cascadilla Press. Available at https://msuacquisition.files.wordpress. com/2010/09/munn-miller-schmitt2006.pdf

Neale, Stephen. 1990. Descriptions. Cambridge, Massachusetts, London, England: The MIT Press. 
Pan, Haihua \& Jiang, Yan. 2015. The bound variable hierarchy and donkey anaphora in Mandarin Chinese. International Journal of Chinese Linguistics 2(2). 159-192. DOI: https://doi.org/10.1075/ ijchl.2.2.01pan

Parsons, Terry. 1978. Pronouns as Paraphrases. Amherst: University of Massachusetts dissertation.

Philip, William. 1991. Spreading in the acquisition of universal quantifiers. In Bates, Down (ed.), Proceedings of the Tenth West Coast Conference on Formal Linguistics, 359-373. Stanford: CSLI Publications.

Philip, William. 1992. Distributivity and logical form in the emergence of universal quantification. In Barker, Chris \& Dowty, David (eds.). Proceedings of the $2^{\text {nd }}$ Conference on Semantic and Linguistic Theory, Ohio State Working Papers in Linguistics 40. 327-346. The Ohio State University. DOI: https://doi.org/10.3765/salt.v2i0.3029

Philip, William. 1995. Event quantification in the acquisition of universal quantification. Amherst: University of Massachusetts dissertation.

R Development Core Team. 2017. R: A Language and Environment for Statistical Computing. Vienna: R Foundation for Statistical Computing. Retrieved from http://www.r-project.org/.

Roeper, Thomas \& de Villiers, Jill. 1991. The emergence of bound variable structures. In Reuland, Eric \& Abraham, Werner (eds.), Knowledge and language: Orwell's problem and Plato's problem, 105-139. Dordrecht: Kluwer. DOI: https://doi.org/10.1007/978-94-011-1840-8_6

Rooth, Mats. 1987. Noun phrase interpretation in Montague Grammar, File Change Semantics, and Situation Semantics. In Gärdenfors, Peter (ed.), Generalized quantifiers: Linguistic and logical approaches, 237-268. Dordrecht: D. Reidel. DOI: https://doi.org/10.1007/978-94-009-3381-1_9

Rooth, Mats. 1992. A theory of focus interpretation. Natural Language Semantics 1(1). 75-116. DOI: https://doi.org/10.1007/BF02342617

Schwarzschild, Roger. 1994. Plurals, presuppositions and the sources of distributivity. Natural Language Semantics 2(3). 201-248. DOI: https://doi.org/10.1007/BF01256743

Schwarzschild, Roger. 1996. Pluralities. London: Kluwer Academic. DOI: https://doi. org/10.1007/978-94-017-2704-4

Sharvy, Richard. 1980. A more general theory of definite descriptions. The Philosophical Review 89. 607-624. DOI: https://doi.org/10.2307/2184738

Singh, Raj \& Wexler, Ken \& Astle-Rahim, Andrea \& Kamawar, Deepthi \& Fox, Danny. 2016. Children interpret disjunction as conjunction: Consequences for theories of implicature and child development. Natural Language Semantics 24(4). 305-352. DOI: https://doi.org/10.1007/ s11050-016-9126-3

Takahashi, Mari. 1991. Children's interpretation of sentences containing 'every'. In Maxfield, Thomas L. \& Plunkett, Bernadette (eds.), University of Massachusetts Occasional Papers Special Edition, Papers in the Acquisition of Wh: Proceedings of the UMASS Roundtable 17(1). 303-329. Amherst, MA: Graduate Linguistic Students' Association, University of Massachusetts. Available at: http://scholarworks.umass.edu.umop/vol17/iss1/15

Tieu, Lyn, Manuel Križ \& Chemla, Emmanuel. 2019. Children's acquisition of homogeneity in plural definite descriptions. Frontiers in Psychology 10. 1-25. DOI: https://doi.org/10.3389/ fpsyg.2019.02329 
Tieu, Lyn \& Romoli, Jacopo \& Zhou, Peng \& Crain, Stephen. 2016. Children's knowledge of free choice inferences and scalar implicatures. Journal of Semantics 33. 269-298. DOI: https://doi. org/10.1093/jos/ffv001

von Fintel, Kai-Uwe. 1994. Restrictions on quantifier domains. Amherst: University of Massachusetts dissertation. Available at: https://semanticsarchive.net/Archive/jA3N2IwN/fintel-1994-thesis. pdf

Yoon, Youngeun. 1994. Weak and strong interpretations of quantifiers and definite NPs in English and Korean. Austin: University of Texas dissertation.

Yoon, Youngeun. 1996. Total and partial predicates and the weak and strong interpretations. Natural Language Semantics 4(3). 217-236. DOI: https://doi.org/10.1007/BF00372820 